Proceedings of the 12th International Symposium on Physics of Materials, Prague, September 4-8, 2011

\title{
Work Hardening of Magnesium Single Crystals Deformed to Stage B at Room Temperature
}

\author{
B. SuŁkowski* AND B. MikuŁowski \\ AGH University of Science and Technology, Department of Metallic Materials and Nano-Engineering \\ Faculty of Non-Ferrous Metals, al. A. Mickiewicza 30, 30-059 Cracow, Poland
}

\begin{abstract}
Magnesium single crystals of purity $(99.8 \mathrm{wt} \%$ ) deformed to stage B on the work-hardening curve at the temperature of $293 \mathrm{~K}$ and at a strain rate of $10^{-3} \mathrm{~s}^{-1}$ were investigated. The modified Bridgman method was used to obtain the crystals of the preferred orientation of $(0001)\langle 11 \overline{2} 0\rangle$ as primary slip system. By using the method based on the experimental gradient matrix, the activity of slip systems was obtained in magnesium single crystals deformed to shear strain $1.2 \gamma$, where well developed stage B of work hardening was observed. It was shown that primary $(0001)\langle 11 \overline{2} 0\rangle$ slip system was dominant in the whole investigated range of the examined deformation. The observation and analysis of etch pits on the $\{\overline{1} 2 \overline{1} 0\}$ plane showed the heterogeneous distribution of dislocations formed during deformation into walls of dislocations perpendicular to the (0001) slip plane. The suggested model of work hardening of magnesium single crystals, which is worth taking into consideration, shows the influence of the long-range stress field derivating from the groups of dislocations arranged in dislocation walls.
\end{abstract}

PACS: 81.40.Ef, 61.72.Ff, 61.72.Hh, 61.72.Lk, 61.72.Hh, 61.72.Hh

\section{Introduction}

Work hardening theories based upon a predominant role of a dislocation interaction mechanism related to fcc metals are transferred to hcp metals like $\mathrm{Mg}, \mathrm{Zn}, \mathrm{Cd}$ deformed by single slip especially in stage B of deformation. There are some differences in work hardening between fcc and hcp metals. The work hardening coefficients $\theta_{\mathrm{A}}$ and $\theta_{\mathrm{B}}$ are temperature dependent $[1,2]$. In hcp metals, there are many types of slip systems with different Burgers vectors. The critical resolved shear stress for the different types of slip systems is up to two order higher than the critical resolved shear stress for basal slip system [3]. The forest dislocation density is too low to completely explain free path of moving basal dislocations.

On the other hand, the dislocation structure developed during deformation of single crystals of metals [4,5] and the walls of dislocations are formed. The purity of single crystals is one of the main factors which has influence in developing dislocation structure $[5,6]$ because it may introduce stress gradient leading to the nonuniform distribution of dislocations. The investigations made by Mikułowski and Książek [6] showed that the dislocations walls formed during the deformation of zinc single crystals strongly affected work hardening.

\section{Experimental details}

Magnesium single crystals (Mg 99.8 wt\%) were grown from melt using the modified Bridgman method. Rods of polycrystalline magnesium were placed in boron nitride mould inside an alumina furnace tube and evacuated using an oil diffusion pump. There were carried out a few series of evacuating to vacuum at least

* corresponding author; e-mail: sul5@agh.edu.pl
$2 \times 10^{-4} \mathrm{hPa}$ and admitting of high purity argon gas (5.0) to a pressure of $0.196 \times 10^{3} \mathrm{hPa}$. When the temperature reached $680^{\circ} \mathrm{C}$, the furnace was cooled down at the rate of $1.5^{\circ} \mathrm{C} / \mathrm{min}$. The obtained single crystals were parallelepiped, $60 \times 3 \times 3 \mathrm{~mm}^{3}$ in dimension. The orientation of the magnesium single crystals was determined by a Bruker D8 Advance diffractometer. Only the single crystals of similar orientation, where the tensile direction was close to [62 85$]$, which preferred the deformation in the $(0001)\langle 11 \overline{2} 0\rangle$ slip system, were investigated. Then the single crystals were etched in a $10 \%$ solution of nitric acid in water and then electropolished for $2 \mathrm{~h}$ at room temperature in a solution of $\mathrm{H}_{3} \mathrm{PO}_{4}$ acid and ethanol (volume ratio $3: 5$ ) with a tantalum cathode operating at $3 \mathrm{~V}$.

The single crystals were deformed by tension at room temperature at a shear strain rate of $10^{-3} \mathrm{~s}^{-1}$ up to $1.5 \gamma$ where well developed stage B of work hardening was observed. To determine the activity of slip systems during tensile deformation of the magnesium single crystals, the method based on experimental gradient matrix was used. This method was established by Chin et al. [7], other authors [8-11] refined this method and performed detailed study of activity of slip systems in deformed copper and zinc single crystals of different orientations. In this method, the shape changes during single or multi slip of single crystal are linked with the slip system activity. The $(0001)\langle 11 \overline{2} 0\rangle,\{10 \overline{1} 0\}\langle 1 \overline{2} 10\rangle$ and $\{11 \overline{2} 2\}\langle 11 \overline{23}\rangle$ slip systems were taken into consideration for the calculation of slip system activity during tension deformation of magnesium single crystals at room temperature. In the middle of two perpendicular sides of the crystals the mesh of twenty five $(5 \times 5)$ points with the space of $0.5 \mathrm{~mm}$ between each point were placed. The measurements of the coordinations of the points and orientation of the crystal before deformation and after $0.4 \gamma, 0.8 \gamma$ and $1.2 \gamma$ allowed to set vectors describing certain volume of deformed mag- 
nesium single crystals. From the shape changes of that volume, it was possible to determine the slip system activity in magnesium single crystals deformed by tension.

The etch pits of dislocations on the surface near the $\{\overline{1} 2 \overline{1} 0\}$ plane of initial and deformed samples were investigated by optical microscope. The electropolished surface was etched in a solution consisting of $10 \mathrm{~g}$ of ammonium chloride dissolved in $50 \mathrm{~cm}^{3}$ of water [12]

Transmission electron microscopy was used to determine the dislocations density in initial and deformed magnesium single crystals. The dislocations were observed on the basal (0001) plane and on the prismatic $\{11 \overline{2} 0\}$ plane. Using Struers Secotom 10 cut machine, about $2 \mathrm{~mm}$ thin slices were cut from the middle of the initial and the deformed magnesium single crystals. There were two kinds of slices, those with planar section parallel to the (0001) plane and those with planar section parallel to the $\{11 \overline{2} 0\}$ plane. Then the slices were thinned by chemical polishing in a solution of $10 \%$ nitric acid and 90\% distilled water and electropolished in $1 \%$ perchloric acid in ethanol using TenuPol 5 to obtain the samples for observations in Philips CM-20 microscope.

\section{Results and discussion}

Figure 1 presents a work hardening curve of $\mathrm{Mg}$ (99.8 wt\%) single crystal for basal slip at room temperature. The critical resolved shear stress is $\tau_{\mathrm{CRSS}}=$ 1.01 MPa. The work hardening curve consists of two stages - easy glide stage A is followed by a relatively short stage $\mathrm{B}$. The transition from stage A to stage $\mathrm{B}$ is gradual and reaches $0.38 \gamma$. The work hardening coefficients at stages $\mathrm{A}$ and $\mathrm{B}$ are $\theta_{\mathrm{A}}=3.11 \mathrm{MPa}$ and $\theta_{\mathrm{Bmax}}=27.31 \mathrm{MPa}$, respectively (stage $\mathrm{A}$ is nonlinear and therefore the above value is an average one).

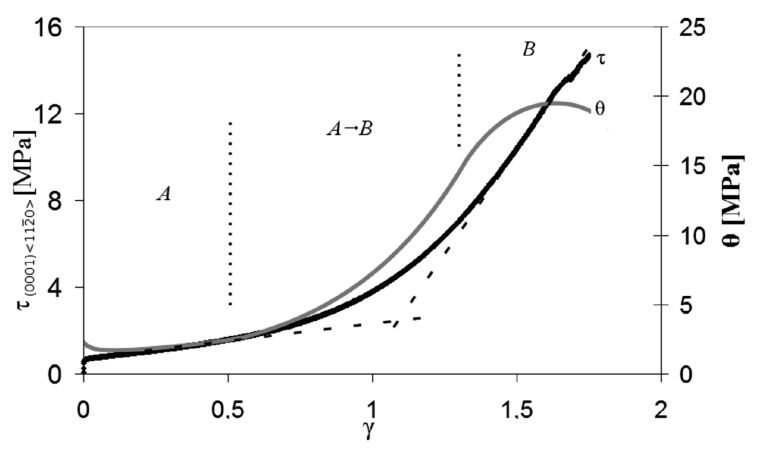

Fig. 1. Work hardening curve of $\mathrm{Mg}$ (99.8 wt\%) single crystal deformed by tension at room temperature.

Figure 2 shows slip systems activity of $\mathrm{Mg}(99.8 \mathrm{wt} \%)$ single crystals deformed by tension at room temperature. For the given orientation of obtained single crystals (tensile direction parallel to $[62 \overline{8} 5])$, the basal slip system (0001) $[11 \overline{2} 0]$ was activated as primary. There was no change of the primary slip system, and the activity of secondary slip systems is very low, even after $1.2 \gamma$ of deformation.

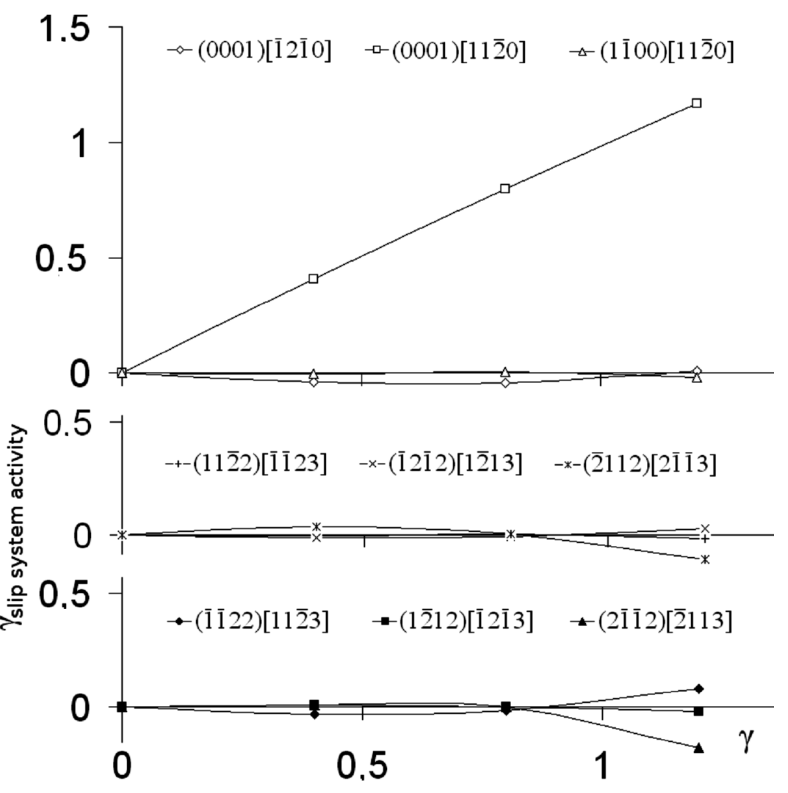

Fig. 2. Slip system activity of $\mathrm{Mg}$ (99.8 wt\%) single crystal deformed by tension at room temperature (tensile direction parallel to $[62 \overline{8} 5])$.

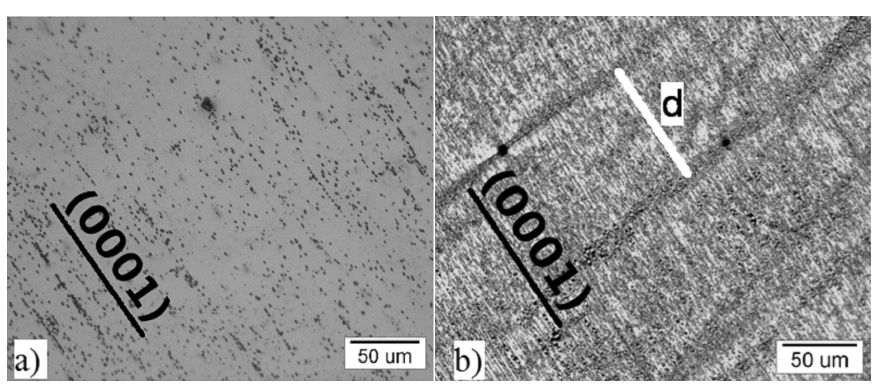

Fig. 3. Etch pits of dislocations on a surface near $\{\overline{1} 2 \overline{1} 0\}$ plane of initial material (a), and of $\mathrm{Mg}$ (99.8 wt\%) single crystals deformed up to $0.6 \gamma$ at room temperature $(\mathrm{b})$.

The etch pits of dislocations, on the surface near the $\{\overline{1} 2 \overline{1} 0\}$ plane, in the initial material and in the deformed up to $0.6 \gamma \mathrm{Mg}(99.8 \mathrm{wt} \%)$ single crystals are shown in Fig. 3.

The initial density of etch pits of dislocations was $0.3 \times 10^{6} \mathrm{~cm}^{-2}$ (Fig. 3a) and after $0.6 \gamma$ the density of etch pits of dislocations reached the value of $24.2 \times 10^{6} \mathrm{~cm}^{-2}$ (Fig. 3b). The etch pits of dislocations showed in Fig. 3b are mostly arranged in dislocations walls perpendicular to the (0001) plane. Such arrangements of etch pits of dislocations were also observed in copper single crystals deformed by tension at room temperature [13] and in bent zinc single crystals [14]. The dislocations walls in $\mathrm{Mg}$ (99.8 wt\%) single crystals deformed by tension were formed during deformation. The average distance $\bar{d}$ between disloction walls observed in Fig. 3b was decreased during deformation, as is shown in Fig. 4. First disloca- 


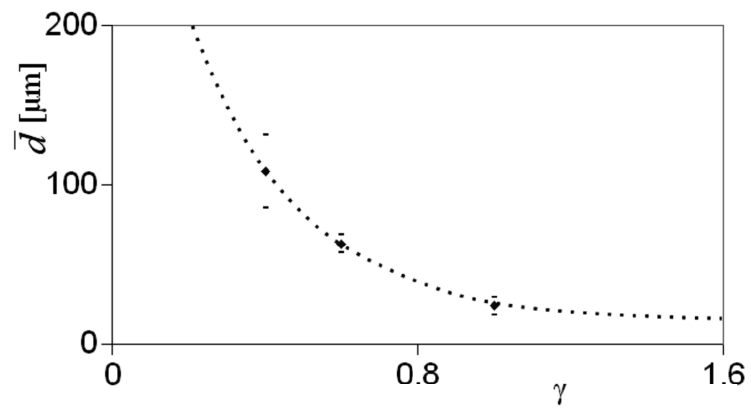

Fig. 4. Average distance $\bar{d}$ between dislocation walls of $\mathrm{Mg}(99.8 \mathrm{wt} \%)$ single crystals deformed by tension at room temperature.

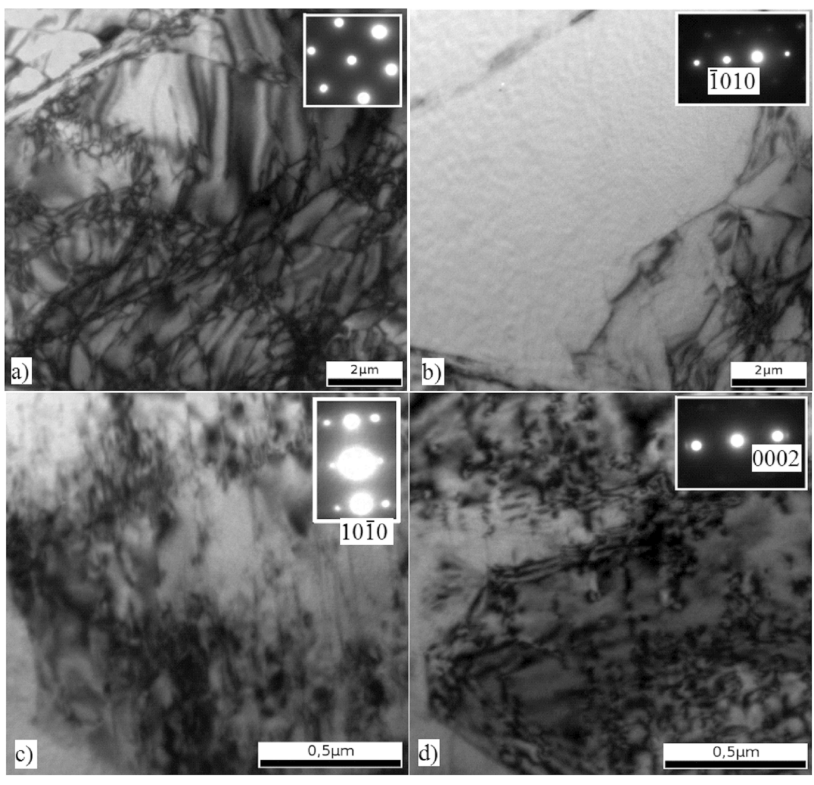

Fig. 5. Dislocation structure of $\mathrm{Mg}(99.8 \mathrm{wt} \%$ ) single crystals deformed up to $1.4 \gamma$ by tension at room temperature. Plane (0001) (a), (b); plane $\{\overline{1} 2 \overline{1} 0\}$ (c), (d).

tions walls appeared at $0.4 \gamma$, where stage $\mathrm{A}$ ended and the transition from stage A to stage B started.

The dislocation structures formed at stage B are shown in Fig. 5. We can see that the distribution of the dislocations is heterogeneous.

The dislocation density was increasing during deformation (Fig. 6). Before the deformation, the basal dislocation density is at least two orders higher than the forest dislocation density, but during the deformation, it was increasing slower than the forest dislocation density. The basal and the forest dislocation density before deformation were $5.97 \times 10^{8} \mathrm{~cm}^{-2}$ and $1.23 \times 10^{6} \mathrm{~cm}^{-2}$, respectively. After $1.4 \gamma$, the basal and the forest dislocation density were $4.71 \times 10^{9} \mathrm{~cm}^{-2}$ and $4.8 \times 10^{7} \mathrm{~cm}^{-2}$, respectively.

Experimental investigations of work hardening of metals single crystals allowed us to establish the relationship

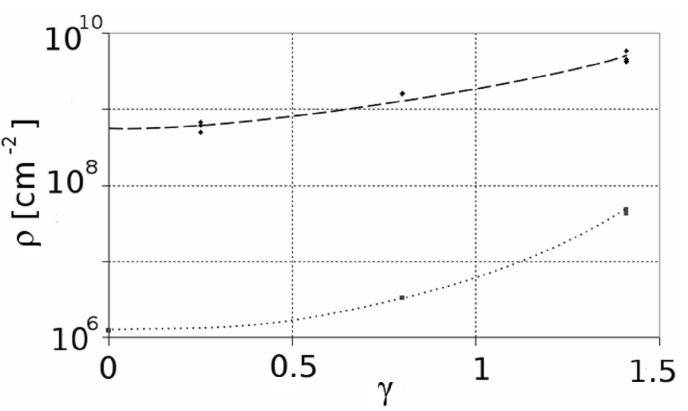

Fig. 6. Dislocation density of $\mathrm{Mg}$ (99.8 wt\%) single crystals deformed by tension at room temperature. Dashed line - basal dislocation density, dotted line forest dislocation density.

between the flow stress $\tau$ and the square root of the dislocation density $\rho[15,16]$, with proportional factor $\alpha$. The $\alpha$ values measured in experiments were in range between $0.1-1$ for fcc metals and $\alpha$ values for hcp metals as large as 2.6 have been reported [16]. Theoretical investigations made by Püschl and Schoeck [17] showed that $\alpha$ value for hcp metals was not higher than $\approx 1$. On the other hand, the dislocation structure developed during deformation of single crystals of metals $[4,5]$ led to the formation of cell structure. Langford and Cohen [18] investigated severely drawn iron wires and proposed a relationship, which takes into consideration the cell-wall segments, where the contribution to the flow stress induced by cell-wall segments was described by proportional factor $\alpha_{3}$.

Sułkowski et al. [19] investigated by electron backscattering diffraction (EBSD) technique $\mathrm{Mg}$ single crystals deformed by tension at room temperature and did not observe twinning, but there was some local rotation of $\approx 7^{\circ}$ of the microstructure resulting from rotations around the $\langle\overline{1} 100\rangle$ axis. The explanation was that during the deformation by tension at room temperature of $\mathrm{Mg}$ single crystals oriented for single slip, the dislocation walls, consisting of edge basal dislocations, were formed, causing consequently a change in local misorientation.

The relationship that links the contribution of dislocation density $\rho$ and dislocation walls to the flow stress $\tau$ in $\mathrm{Mg}(99.8 \mathrm{wt} \%)$ single crystals deformed by tension at room temperature can be written as

$$
\tau=\tau_{0}+\alpha_{1} G b \sqrt{\rho_{\mathrm{b}}}+\alpha_{2} G b \sqrt{\rho_{\mathrm{f}}}+\alpha_{3} G b \bar{d}^{-1},
$$

where $\tau_{0}$ is friction stress, $\rho_{\mathrm{b}}$ is the basal dislocation density, $\rho_{\mathrm{f}}$ is the forest dislocation density, $\alpha_{1}$ describes the basal-basal dislocation interaction, $\alpha_{2}$ describes the basal-forest dislocation interaction and $\alpha_{3}$ describes the basal-dislocation walls interaction, $G$ is the shear modulus, $b$ - the Burgers vector of glide dislocations, and $\bar{d}$ - distance between the dislocation walls. 
In our calculations, $\tau_{0}=0.49 \mathrm{MPa}, \alpha_{1}=0.15$, which corresponds to the weak basal-basal dislocation interaction, $\alpha_{2}=1$, which describes strong basal-forest dislocation interaction, $\alpha_{3}=5.2$ [17], $G=16.4 \mathrm{GPa}$, $b=0.321 \mathrm{~nm}$. The values $\bar{d}, \rho_{\mathrm{b}}, \rho_{\mathrm{f}}$ were taken from Figs. 4 and 6, respectively. The results are showed in Fig. 7.

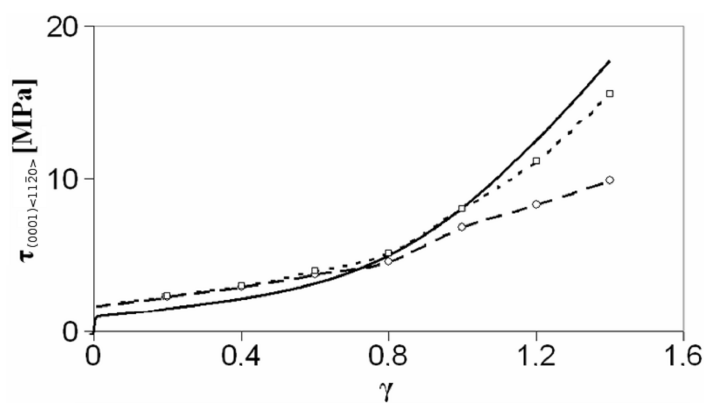

Fig. 7. $\tau-\gamma$ relationship of $\mathrm{Mg}(99.8 \mathrm{wt} \%)$ single crystal deformed by tension at room temperature - full line, and calculated from Eq. (1) - dotted line. Dashed line - calculated from (1) without last module.

From Fig. 7, it can be seen that when only the dislocation density is considered (dashed line), there is no agreement with the experimentally obtained curve and structural strengthening mechanisms should be taken into consideration. The calculated curve (Fig. 7, dotted line) from Eq. (1) is in a good agreement with work hardening curve obtained from experiment of $\mathrm{Mg}$ (99.8 wt\%) single crystal deformed by tension at room temperature.

\section{Conclusions}

1. Work hardening curve of $\mathrm{Mg}$ single crystals (99.8 wt\%) deformed by tension at room temperature consists of two stages. Easy glide stage A is followed by a relatively short stage $\mathrm{B}$. The transition from stage $\mathrm{A}$ to stage $\mathrm{B}$ is gradual and reaches $0.38 \gamma$.

2. The (0001)[11 $\overline{2} 0]$ slip system was the primary slip system in the whole investigated range of deformation.

3. There was no twinning observed.

4. During the deformation of $\mathrm{Mg}(99.8 \mathrm{wt} \%)$ single crystals by tension at room temperature dislocation walls perpendicular to the basal slip plane were formed.
5. The dislocation walls contribute to the flow stress $\tau$ which can be expressed by Eq. (1).

\section{Acknowledgments}

The authors would like to express their thanks to Prof. J. Dutkiewicz from Institute of Metallurgy and Materials Science of Polish Academy of Sciences in Kraków, for help and encouragement in TEM investigations. The project was supported by the Polish Committee for Scientific Research, Agreement No. 18.18.180.481 and was performed within the framework of the statutory activity (11.11.180.250) of the Department of Metallic Materials and Nano-Engineering at University of Science and Technology in Kraków.

\section{References}

[1] M. Boček, G. Hötzsch, B. Simmen, Phys. Status Solidi 7, 833 (1964).

[2] B. Wielke, W. Tikvic, A. Svobodová, P. Lukáč, Acta Metall. 25, 1071 (1977).

[3] H. Tonda, S. Ando, Metall. Mater. Trans. A 33, 831 (2002).

[4] H. Mughrabi, Acta Metall. 31, 1367 (1983).

[5] J. Washburn, E.R. Parker, Trans. AIME 194, 1076 (1952).

[6] B. Mikułowski, M. Książek, Key Eng. Mater. 97-98, 395 (1994).

[7] G.Y. Chin, R.N. Thurston, E.A. Nesbitt, Trans. AIME 236, 69 (1966).

[8] L. Johnson, Trans. AIME 245, 245 (1969).

[9] Z.S. Basinski, S.J. Basinski, Philos. Mag. 84, 213 (2004).

[10] J.N. Florando, M. Rhee, A. Arsenlis, M.M. Leblanc, D.H. Lassila, Philos. Mag. 86, 795 (2006).

[11] M.S. Szczerba, P. Pałka, Arch. Metall. Mater. 54, 57 (2009).

[12] M. Sasaki, K. Marukawa, Trans. JIM 18, 540 (1977).

[13] J.D. Livingston, Acta Metall. 10, 229 (1962).

[14] P.P. Sinha, P.A. Beck, J. Appl. Phys. 32, 1222 (1961).

[15] F.F. Lavrentev, Yu.A. Pokhil, Z. Zolotukhina, Mater. Sci. Eng. 32, 113 (1978).

[16] V.L. Vladimirova, F.F. Lavrentev, Sov. Phys. Solid State 15, 379 (1973).

[17] W. Püschl, G. Schoeck, Crystal Res. Technol. 19, 303 (1984).

[18] G. Langford, M. Cohen, Metall. Trans. A 6, 901 (1975).

[19] B. Sułkowski, R. Chulist, W. Skrotzki, B. Mikułowski, Cryst. Res. Technol. 46, 439 (2011). 